\title{
The evaluation of prognostic value of acute phase reactants in the COVID-19
}

\author{
Yormaz B ${ }^{1}$, Ergun $D^{1}$, Tulek B ${ }^{1}$, Ergun $\mathrm{R}^{1}$, Korez $\mathrm{KM}^{2}$, Suerdem $\mathrm{M}^{1}$, Kanat $\mathrm{F}^{1}$ \\ Department of Chest Disease, Faculty of Medicine, Selcuk University, Konya, Turkey. \\ serdaryormaz@gmail.com
}

\section{ABSTRACT}

AIMS: The aim of this study was to explain the demographic data, comorbidity and laboratory findings of our first cases in COVID-19 pneumonia in our country.

METHODS: We gathered the data of COVID-19 pneumonia participants from our electronic medical system, including daily medical knowledge and laboratory, radiological, and microbiological results between March 10 to April 7, 2020.

RESULTS: Totally, 125 patients, whose findings were compatible with COVID-19, were included in the study, 42 patients were excluded from the study. The distribution of genders was, 39 females (46.9\%), 44 males (53.01\%), the average age was $56.36 \pm 16.25$ (19-85). Hypertension above 60 years of age and diabetes mellitus under 60 years of age were the most common comorbidities. Neutrophils/ Lymphocyte percent (\% NLR) was noted in 44 (53.01\%) patients, average: 3 (range 1.78-4.63). There was a statistically significant and positive relationship between D-dimer and C Reactive Protein (CRP) and ferritin.

CONCLUSION: We detected that comorbidities, which were seen at COVID-19 disease differ according to the patients age. Besides that D-dimer, ferritin and CRP outcomes were particularly high and had a significant correlation with COVID-19 severity (Tab. 3, Fig. 2, Ref. 25). Text in PDF www.elis.sk

KEY WORDS: COVID-19, prognosis, acute phase reactan.

\section{Introduction}

World Health Organization (WHO) reported pneumonia cases with an unidentified aetiology in Wuhan, Hubei province, republic of China on December 31, 2019, first. The causative agent was identified as a new Coronavirus (2019-nCoV), which has never been detected in humans before, on January 7, 2020. Afterwards, 2019-nCoV disease's name was recognized as COVID-19, and the virus was named as SARS-CoV-2 due to its close resemblance to SARS CoV. On March 11, 2020, COVID-19, becoming an universal nightmare, was declared a pandemic by the World Health Organization $(1,2)$.

As in all countries, COVID-19 continues to spread rapidly, in our country as well. The first cases of COVID-19 in Turkey were officially noticed on March 10, 2020. In this global pandemic, every community makes analysis of its demographic data on this newly introduced virus, searching for the way to diagnose risk factors and how to take necessary steps. We have planned this study in order to determine the diseases accompanying COVID-19 and risk

${ }^{1}$ Selcuk University, Faculty of Medicine, Department of Chest Diseases, Konya, Turkey, and ${ }^{2}$ Selcuk University, Faculty of Medicine, Department of Biostatistics, Konya, Turkey

Address for correspondence: B. Yormaz, Department of Chest Disease, Faculty of Medicine, Selcuk University, 42075, Konya, Turkey.

Phone: +90.532.6900531, Fax: +90.332.2412684 factors in our country, and also to determine the parameters, which are crucial for COVID-19, through laboratory findings.

\section{Methods}

\section{Data collection}

We enrolled 125 patients with COVID-19 that were hospitalized at Selcuk University Hospital, department of Pulmonary Disease between March 10 to April 7, 2020 retrospectively. Totally, 125 patients, whose clinical and tomography findings were compatible with COVID 19, were included in the study, patients with negative PCR results were excluded from the study. 33t patients carrying out the religious ibaadet of the outgoing Saudi Arabia and a current ümrec consisted of Turkish citizens. The study was approved by the local Ethics Committee of the University. The research was conducted in accordance with the principles of the Declaration of Helsinki. We gathered the data of participants from our electronic medical system, including daily medical knowledge and laboratory, radiological, and microbiological results.

\section{Inclusion criteria}

All of the participants were defined according to their clinical symptoms (suffering from fever, cough, sputum and shortness of breath), contact history, positive outcomes of RT-PCR (real-time reverse transcriptase-polymerase chain reaction assay), which were taken from the patients by nasal and pharyngeal swaps (guided according to WHO advices). 
Tab. 1. Demographic characteristics of the patients.

\begin{tabular}{ll}
\hline Characteristics & Patients $(\mathrm{n}=83)$ \\
\hline Age (years), mean $\pm \mathrm{SD}(\min -\max )$ & $56.36 \pm 16.25(19-85)$ \\
\hline Age levels, $\mathrm{n}(\%)$ & $14(16.87)$ \\
$19-40$ years & $33(39.76)$ \\
$41-60$ years & $36(43.37)$ \\
$60+$ years & $39(46.99)$ \\
\hline Gender, $\mathrm{n}(\%)$ & $44(53.01)$ \\
Female & \\
Male & $52(62.65)$ \\
\hline Contact, $\mathrm{n}(\%)$ & $31(37.35)$ \\
Yes & \\
No & $33(39.76)$ \\
\hline Overseas Travel, $\mathrm{n}(\%)$ & $50(60.24)$ \\
Yes & \\
No & $53(63.86)$ \\
\hline Comorbidity, $\mathrm{n}(\%)$ & $30(36.14)$ \\
Yes & \\
No & $30(36.14)$ \\
\hline Comorbidity Numbers, $\mathrm{n}(\%)$ & $30(36.14)$ \\
0 & $10(12.05)$ \\
1 & $7(8.43)$ \\
2 & $5(6.02)$ \\
3 & $1(1.20)$ \\
4 & \\
5 & $26(31.33)$ \\
\hline Cigarette, $\mathrm{n}(\%)$ & $57(68.67)$ \\
Yes & $15(57.69)$ \\
No & $11(42.31)$ \\
Still smoke, $\mathrm{n}(\%)$ & $22.38 \pm 12.14$ \\
Ex smoke, $\mathrm{n}(\%)$ & $(5-50),(\mathrm{n}=26)$ \\
Cigarette (Packet/year), mean \pm SD & \\
\hline Data are described as the mean \pm standard deviation $(\min -\mathrm{max})$ or counts $(\mathrm{n})$ and \\
percentages $(\%)$ & \\
&
\end{tabular}

\section{Excluding criteria}

The patients, whose HRCT were consistent with COVID-19 pneumonia radiologic signs, however PCR test results were negative, were excluded from the research.

Tab. 2. Comorbidities according to the frequency of occurrence.

\begin{tabular}{|c|c|c|c|c|c|c|}
\hline \multirow{2}{*}{ Comorbidity } & \multicolumn{2}{|c|}{$\begin{array}{c}\text { Total } \\
(\mathrm{n}=92)\end{array}$} & \multicolumn{2}{|c|}{$\begin{array}{c}\text { Age }(<60) \text { years } \\
(n=22)\end{array}$} & \multicolumn{2}{|c|}{$\begin{array}{c}\text { Age }(\geq 60) \text { years } \\
(n=31)\end{array}$} \\
\hline & $\begin{array}{l}\text { Count } \\
\text { (n) }\end{array}$ & $\begin{array}{c}\text { Percentages } \\
(\%)\end{array}$ & $\begin{array}{l}\text { Count } \\
\text { (n) }\end{array}$ & $\begin{array}{c}\text { Percentages } \\
(\%)\end{array}$ & $\begin{array}{l}\text { Count } \\
\text { (n) }\end{array}$ & $\begin{array}{c}\text { Percentages } \\
(\%)\end{array}$ \\
\hline Hypertension & 27 & 29.35 & 8 & 15.10 & 19 & 35.80 \\
\hline Diabetes Mellitus & 20 & 21.74 & 10 & 18.90 & 10 & 18.90 \\
\hline Coronary Artery Disease & 8 & 8.70 & 0 & 0.00 & 8 & 15.10 \\
\hline Heart Failure & 8 & 8.70 & 3 & 5.70 & 5 & 9.40 \\
\hline Asthma & 6 & 6.52 & 4 & 7.50 & 2 & 3.80 \\
\hline Other Disease & 6 & 6.52 & 3 & 5.70 & 3 & 5.70 \\
\hline COPD & 5 & 5.43 & 1 & 1.90 & 4 & 7.50 \\
\hline Malignancy & 3 & 3.26 & 0 & 0.00 & 3 & 9.70 \\
\hline Chronic Renal Failure & 3 & 3.26 & 1 & 1.90 & 2 & 3.80 \\
\hline Gastrointestinal Disease & 3 & 3.26 & 1 & 1.90 & 2 & 3.80 \\
\hline Cerebrovascular Disease & 2 & 2.17 & 1 & 1.90 & 1 & 1.90 \\
\hline Rheumatism & 1 & 1.09 & 1 & 1.90 & 0 & 0.00 \\
\hline HBV & 0 & 0 & 0 & 0.00 & 0 & 0.00 \\
\hline HIV & 0 & 0 & 0 & 0.00 & 0 & 0.00 \\
\hline Autoimmune Disease & 0 & 0 & 0 & 0.00 & 0 & 0.00 \\
\hline
\end{tabular}

\section{Collection of samples}

Real-time reverse transcriptase-polymerase chain reaction assay for COVID-19

All of the samples were gathered from the nasopharyngeal swabs in all the patients in an isolated swap room. Extracted nucleic acid samples were tested for SARS-CoV-2 with LightCycler 480 real-time PCR system (Roche, Switzerland) in accordance with firm's instructions; $5 \mu \mathrm{L}$ of extracted RNA were added into $20 \mu \mathrm{L}$ of the reaction mixture. Each $20 \mu \mathrm{L}$ reaction mixture contained 12 $\mu \mathrm{L}$ of qRT-PCR reactant, $4 \mu \mathrm{L}$ of qRT-PCR enzyme Mix. Molecules were incubated at $50{ }^{\circ} \mathrm{C}$ for $10 \mathrm{~min}$ and $95{ }^{\circ} \mathrm{C}$ for $5 \mathrm{~min}$ followed by 40 cycles at $95^{\circ} \mathrm{C}$ for $10 \mathrm{~s}$ and $55^{\circ} \mathrm{C}$ for $40 \mathrm{~s}$. Besides that, the samples were subjected to melting curve analyses $\left(95^{\circ} \mathrm{C}\right.$ for $5 \mathrm{~s}$ and $65^{\circ} \mathrm{C}$ for $1 \mathrm{~min}$ followed by a gradual increase in temperature to $97{ }^{\circ} \mathrm{C}$ with continuous recording of fluorescence). The results were commented according to the manual kit guideline.

\section{Radiological Features}

High resolution Thorax computed tomography (HRCT), (256 multidetector CT scanner, Siemens Healthcare, Erlangen, Germany) scans were performed in all the participants, when they were admitted to the hospital. Ground glass opacities, consolidation, reticular pattern, and crazy paving pattern were accepted as the diagnostic criteria of typical CT manifestations of COVID-19 (one or more of these findings was considered positive), HRCT scans were performed in the participants firstly after the admission to the hospital and PA thorax graphic daily in the follow up period later $(3,4)$.

Two pulmonary disease specialists, who were experienced in thorax radiology, blinded to RT-PCR outcomes interpreted all the HRCT images reported according to consensus. The specialists reported the outcomes as positive or negative for COVID-19.

\section{Statistical analysis}

All the statistical analyses were performed with $\mathrm{R}$ 3.6.0 (www.r-project.com). Data were presented as the mean \pm standard deviation ( $\min -\max$ ) or median (interquartile range), and described as counts (n) and percentages (\%). Moreover, we also calculated the numbers (n) and percentages (\%) of the patients falling into the risk group for some of the important laboratory parameters. Spearman's rho correlation coefficients were used to evaluate the relationship between D-dimer, CRP and Ferritin. We also showed the relationship between D-dimer, CRP and Ferritin with a 3D surface plot. $p<0.05$ were accepted as statistically significant.

\section{Results}

A total of 125 patients were hospitalized due to COVID 19 pneumonia, 42 patients, whose RT-PCR test were negative were removed from the study. So, we investigated the characteristics of the first 83 patients 
Tab. 3. Laboratory Findings of the patients.

\begin{tabular}{|c|c|c|c|c|}
\hline $\begin{array}{l}\text { Laboratory } \\
\text { findings }(n=83)\end{array}$ & Mean \pm SD & Min-Max & Median (iqr) & n $(\%)$ \\
\hline WBC, $(<3.5 \mathrm{k} / \mathrm{uL})$ & $7.21 \pm 2.58$ & $3.50-13.90$ & $6.84(5.45-8.35)$ & $0(0)$ \\
\hline Neutrophil(k/uL) & $4.94 \pm 2.38$ & $1.50-12.40$ & $4.10(3-6.40)$ & \\
\hline Neutrophil percent (\%) & $64.37 \pm 14.53$ & $7.30-91$ & $66.60(54.95-75.50)$ & \\
\hline Lymphocyte $(<0,95 \mathrm{k} / \mathrm{uL})$ & $1.66 \pm 0.74$ & $0.50-3.70$ & $1.60(1-2.10)$ & $17(20.48)$ \\
\hline Lymphocytes percent (\%) & $24.61 \pm 11.30$ & $5.40-50.30$ & $22.80(16.15-32.80)$ & \\
\hline NLR, $(\geq 3)$ & $3.84 \pm 3.1$ & $0.75-15.70$ & $3(1.78-4.63)$ & $44(53.01)$ \\
\hline Monocyte(k/uL) & $0.60 \pm 0.31$ & $0-1.70$ & $0.52(0.40-0.70)$ & \\
\hline Monocyte percent $(\%)$ & $9.41 \pm 7.56$ & $1.80-70$ & $8.50(7-9.90)$ & \\
\hline $\mathrm{HB},(<10 \mathrm{~g} / \mathrm{dL})$ & $13.07 \pm 1.68$ & $8.80-16.50$ & $13.20(11.95-14.40)$ & $5(6.02)$ \\
\hline PLT, $(<150 \mathrm{k} / \mathrm{uL})$ & $225.01 \pm 89.75$ & $87-629$ & $201(166-257)$ & $12(14.46)$ \\
\hline ALT, (>50 U / L) & $28.18 \pm 23.04$ & $4-140$ & $22(16.50-31.50)$ & $10(12.05)$ \\
\hline $\mathrm{AST},(>50 \mathrm{U} / \mathrm{L})$ & $31.49 \pm 18.72$ & $12-117$ & $25(19.50-35.50)$ & $12(14.46)$ \\
\hline ALB, $(<3 \mathrm{~g} / \mathrm{dL})$ & $4.05 \pm 3.68$ & $2.41-37$ & $3.70(3.44-4)$ & $6(7.23)$ \\
\hline T.BIL, $(>1,38$ mg/L) & $0.50 \pm 0.35$ & $0.01-2.68$ & $0.42(0.31-0.64)$ & $2(2.41)$ \\
\hline ALP(U/L) & $82.47 \pm 38.46$ & $30-351$ & $78(65.50-92.50)$ & \\
\hline GGT, $(>57 \mathrm{U} / \mathrm{L})$ & $46.70 \pm 39.42$ & $8-236$ & $38(19.50-55)$ & $20(24.10)$ \\
\hline $\mathrm{K}(\mathrm{mmol} / \mathrm{L})$ & $4.27 \pm 0.50$ & $2.92-5.90$ & $4.26(3.96-4.51)$ & \\
\hline $\mathrm{NA}(\mathrm{mmol} / \mathrm{L})$ & $138.66 \pm 5.13$ & $124-170$ & $139(136-141)$ & \\
\hline Uric $\operatorname{acid}(\mathrm{mg} / \mathrm{dL})$ & $5.22 \pm 1.87$ & $2.10-10.70$ & $5(3.90-6.10)$ & \\
\hline Creatinine, $(>1,1 \mathrm{mg} / \mathrm{dL})$ & $1.01 \pm 0.86$ & $0.49-7.12$ & $0.81(0.68-1.02)$ & $17(20.48)$ \\
\hline $\mathrm{CK},(>171 \mathrm{U} / \mathrm{L})$ & $114.19 \pm 230.58$ & $9-1508$ & $60(44-93)$ & $9(10.84)$ \\
\hline LDH, (>243 U / L) & $295.49 \pm 319.69$ & $87-3014$ & $244(191-309)$ & $42(50.60)$ \\
\hline Troponin-I, (>17,5 ng /L) & $8.35 \pm 13.24$ & $2.30-99.50$ & $3.80(2.75-6.05)$ & $12(14.46)$ \\
\hline $\mathrm{CKMB},(>6,3 \mathrm{ng} / \mathrm{mL})$ & $1.53 \pm 1.60$ & $0.20-9.50$ & $1(0.60-1.75)$ & $2(2.41)$ \\
\hline PT (sn) & $13.14 \pm 11.47$ & $9.10-105$ & $10.90(10.70-11.35)$ & \\
\hline INR(INR) & $1.09 \pm 0.49$ & $0.85-4.97$ & $1(0.97-1.04)$ & \\
\hline D-DIMER, (>500 ng /mL) & $1003.92 \pm 2611.35$ & $2.59-23600$ & $529(350-861)$ & $44(53.01)$ \\
\hline PROC, $(>0.5 \mathrm{ug} / \mathrm{L})$ & $0.16 \pm 0.36$ & $0.02-2.60$ & $0.05(0.05-0.09)$ & $4(4.82)$ \\
\hline $\mathrm{CRP},(>8 \mathrm{mg} / \mathrm{L})$ & $30.76 \pm 39.16$ & $1.26-171$ & $14.90(5.59-33.90)$ & $56(67.47)$ \\
\hline Ferritin, $(>340 \mathrm{ng} / \mathrm{mL})$ & $292.11 \pm 302.04$ & $5.70-1500$ & $192.20(70-436)$ & $25(30.12)$ \\
\hline
\end{tabular}

of COVID-19 pneumonia. The distribution of genders was, 39 females (46.9\%), 44 males (53.01\%), the average age was 56.36 \pm 16.25 (19-85), 33 patients had overseas travel history, and also 50 patients had history of contact. Provided with the aunt-niece relationship for 6 patients, the suspicious contact history between them was living together in the same house. There was medical staff diagnosed with COVID 19 during the research period in our hospital. 11 participants were current smokers, besides that 15 were ex- smokers (Tab. 1).

There were $53(63.8 \%)$ patients with some comorbidities such as: hypertension, diabetes mellitus, and some patients had more than one comorbidity. The frequency of comorbidities was: Hypertension (n: 27, $32.5 \%$ ), Diabetes Mellitus (n:2 0, 24.10\%), Coronary Artery Disease and heart failure (n: 8, 9.6\%) respectively. When we evaluated comorbidities according to the age, hypertension above 60 years of age was $35.8 \%$ and $15.10 \%$ below 60 years of age. Diabetes mellitus was seen in $18.9 \%$ of patients over 60 years old and under 60 years old (Tab. 2, Fig. 1).

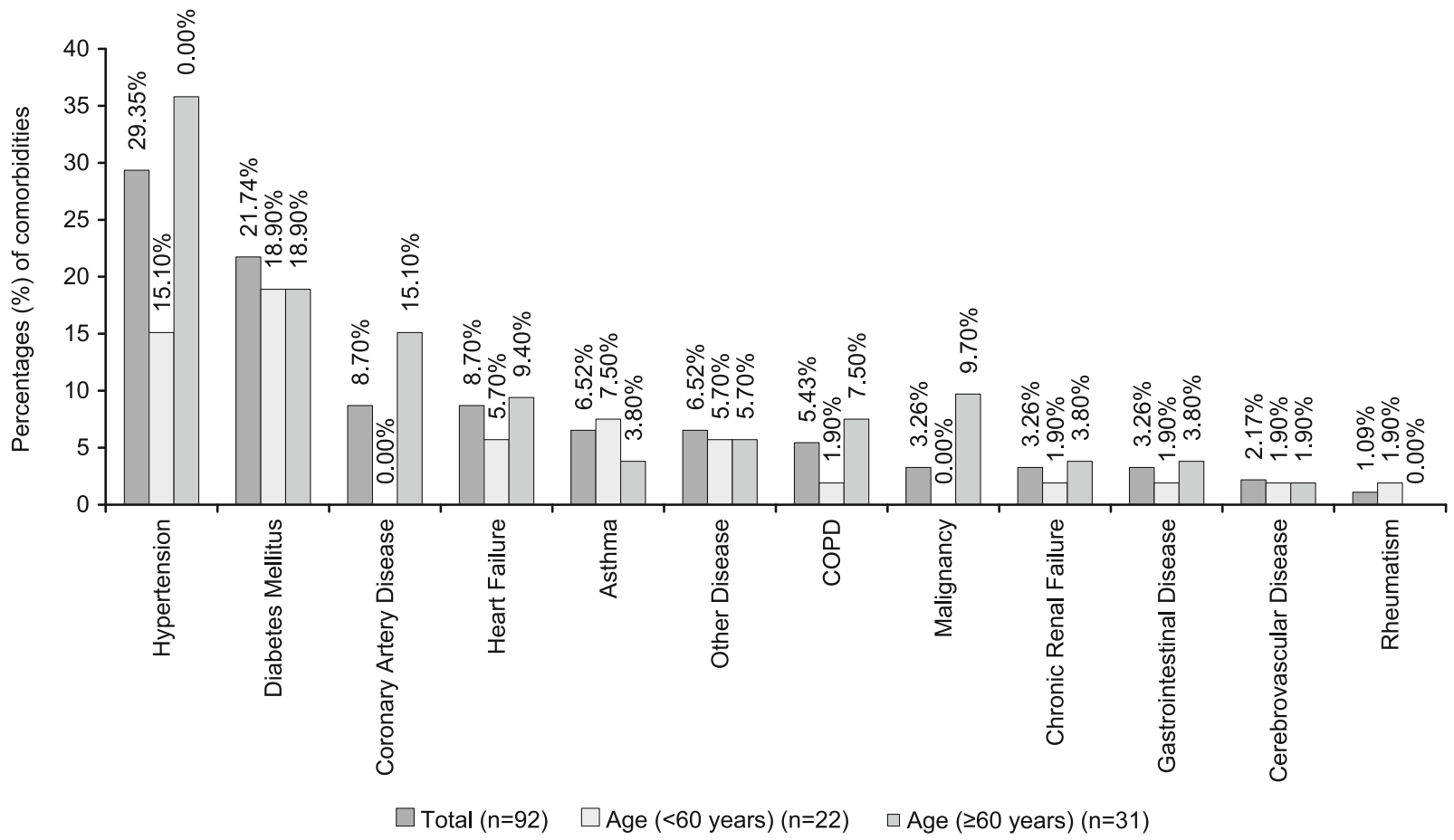

Fig. 1. Comorbidities according to the frequency of occurrence. COPD - chronic obstructive pulmonary disease. 
3D Survace plot of D-dimer vs Ferritin and CRP

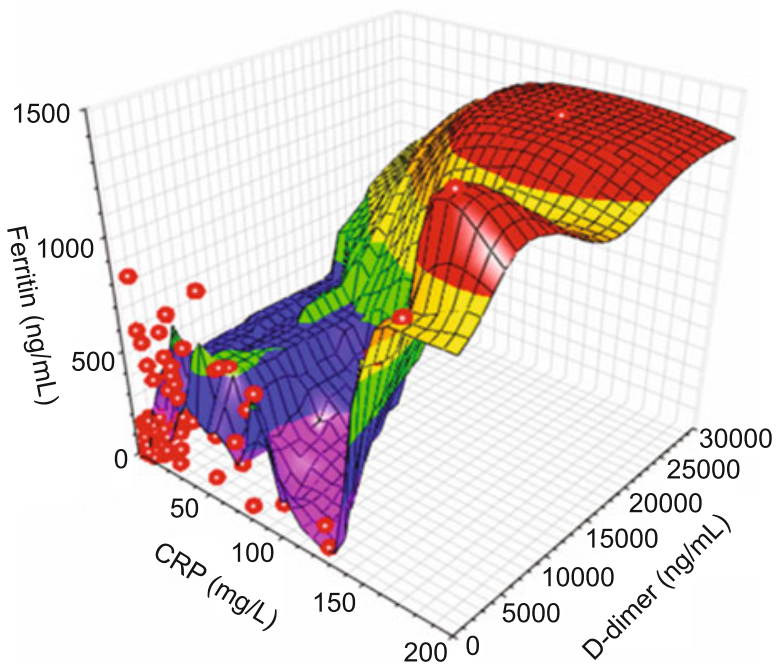

Fig. 2. There was a statistically significant and positive relationship between D-dimer, CRP and Ferritin (Spearman's rho $=0.540, \mathrm{p}<0.001$ and Spearman's rho $=0.466, \mathrm{p}<0.001$, respectively) .

\section{Laboratory parameters}

Evaluated laboratory outcomes included hemograms, biochemical and inflammatory markers which were calculated and detected, when the patients were admitted to the hospital (Tab. 3). There was no leukopenia detected in the study groups, meantime lymphopenia was detected in $17,20.48 \%$ of the patients. Neutrophils/Lymphocyte percent (\% NLR) was noted in 44 (53.01\%) patients. Anaemia was detected in 5 patients $(6.02 \%)$. More than half of the patients $53.01 \%$ showed an elevated NLR, (Neutrophils/Lymphocyte ratio $\geq 3$ ), thrombocytosis was detected in 12 patients (14.46\%), meanwhile elevated ALT (n: 10, $12.05 \%$ ), AST (n: 12, $14.46 \%$ ), total bilirubin (n: 2, $2.41 \%$ ), GGT (n: 20, $24.10 \%$ ), LDH (n: 42, $50.60 \%$ ), values reported as shown. Inflammatory markers and increased creatinine levels attracted an attention, creatinin kinase (n: 9, $10.84 \%$ ), LDH (n: 42, $50.60 \%$ ), Troponin-I (n: 12, $14.46 \%$ ), CKMB (n: 2, $2.41 \%$ ), D-dimer (n: 44, $53.01 \%$ ), Procalcitonin (n: 4, 4.82 \%), CRP (n: 56, $67.47 \%$ ), as shown. More than half of the participants showed elevated levels for NLR ratio, LDH, D-Dimer, CRP markers (Fig. 2).

Procalcitonin values were presented in the normal range in all the participants. The ratios and changes in the COVID-19 patients biochemical outcomes during the stay in the hospital were shown in the Table 3. Especially, Neutrophils/ymphocyte ratio, D-Dimer, CRP and LDH elevated levels reached the maximum level in the first week of hospitalization, consequently, these markers might demonstrate the progression of the illness.

\section{Discussion}

As the number of studies regarding COVID-19 increased, we've observed that demographic data differ from country to country. In the multicentre study in China, the mean age of the patients with COVID-19 was reported to be 48.9 years, and gender distribution was reported to be $42.7 \%$ for females and $57.3 \%$ for males. Among the 55,924 laboratory-approved cases that were reported from February 20, 2020 onwards, the median age was 51 years-old and the majority of the cases were between the ages of 30-69. In our study, the percentage was 53.01 for male gender and 46.9 for female gender. In terms of gender distribution, it was seen that our country is similar to other countries. The average age of our study group was 56.3 and the age distribution was $16.8 \%$ between the ages of $19-40,39.7 \%$ between the ages of $41-60$, and $43.3 \%$ over the age of 60 .

In the meta-analysis involving 8 studies in China and 46248 patients with COVID19, the most common comorbidity was reported to be hypertension (17\%) and diabetes mellitus (8\%), followed by cardiovascular disease $(5 \%)$ and respiratory system diseases $(2 \%)(4,5)$.

In this study, the most common comorbidity was hypertension (n: 27, $32.5 \%$ ). Diabetes mellitus was ranked second with 20 patients $(24.10 \%)$ and third was Coronary Artery Disease and heart failure with 8 patients $(24.10 \%)$. The sequence was similar in terms of frequent comorbidities, but the rates were higher in our study. As it is known, the rate of comorbidity increases with the age. In our study, we considered that the reason for the higher comorbidity rate, as mentioned before, is that $39.7 \%$ of the study group were composed of Umrah citizens coming from Saudi Arabia and the average age of these patients was higher (62.5). In the above mentioned study in China, the approximate age of the patients was 46. Considering the relationship of comorbidities with age, hypertension above 60 years of age was more common in our patient group, while diabetes mellitus was more under 60 years of age. In other words, the frequency of age-related attachment of comorbidities in COVID-19 may also change. Therefore, the age factor should not be forgotten, when evaluating comorbidities.

In SARS pneumonia, distinctive lymphopenia was seen. In various studies, in which lymphocyte values were examined in COVID-19 pneumonia, the rates of $36 \%, 38.9 \%$ and $65 \%$ of lymphopenia were reported (6-9). In our study, lymphopenia was observed in $20.48 \%$ of the patients with COVID-19. It is now recognized that in cases with COVID-19, lymphopenia, boosted neutrophil number and as a consequence of this, the rate of neutrophil/lymphocyte (NLR) increased. In our study, in 53 percent of the patients, a remarkable rise in NLR was observed (10).

In various studies, a decreased amount of serum and the relation of this decreased value with viral load were shown in COVID-19. In another study, hypoalbuminemia was noticed in $35 \%$ of COVID-19 pneumonia, and this situation was shown to be associated with an increased risk of mortality. As death has not yet happened in our study group, we could not comment on the effect of hypoalbuminemia on mortality. In this study, hypoalbuminemia was seen at the rate of $7.2 \%$. This rate was lower, when compared to the other studies. We think that this is not because our study group consisted of the patients with lower general situation and in need of intensive care follow-up, but rather because of the patients, who were followed up in a stable service (11-13). 
$628-633$

Procalcitonin (PCT) is an important acute phase reactant in evaluating the diagnosis and treatment success of bacterial infections. Its normal levels were $<0.5 \mathrm{ng} / \mathrm{mL}$. It rarely exceeded 0.5 $\mathrm{ng} / \mathrm{mL}$ in viral infections. In the study evaluating 236 patients with viral infections, only 3 patients had a level $>2 \mathrm{ng} / \mathrm{ml}$. In the cases of COVID-19, we observed that PRC elevation is $0 \%$ in the study of Chen and his colleagues, and $3 \%$ in the study of Wang and his colleagues (Huang, Wang). In our study, PRC was high in only $4(4.8 \%)$ patients. In this respect, it was similar to other studies. CRP is one of the most frequently used acute phase reactants in the clinic and it is a significant indicator of inflammation. In many infectious and non-infectious inflammatory conditions, serum CRP levels increase. In the studies carried out for COVID-19, we saw that CRP values were high. In our study, 67.47 percent of the patients had a high CRP value $(14,15)$.

Serum ferritin used in the diagnosis of iron deficiency anaemia is an acute phase reactant and it may increase in viral infections. In the studies carried out for the patients with COVID-19, ferritin level was found to be significant in certain studies, whereas it was referred to be insignificant in certain studies. In this study, ferritin height was seen in 30.12 percent of the patients $(16,17)$.

D-dimer is the product of fibrin destruction, which occurs following the activation of the fibrinolytic system. Today, it is among the best laboratory tests that show coagulation activity. In the studies on D-dimer levels in pneumonia in adults, the height of D-dimer has been reported to be important in determining the severity of pneumonia and early diagnosis of sepsis being developed in these patients. In the study of Yu and his colleagues in China, D-dimer levels of the patients with COVID-19 were compared to the level of D-dimer seen in bacterial pneumonia. D-dimer level was found to be associated with inflammation in patients with $\mathrm{CO}-$ VID-19, and anticoagulant therapy was recommended for these patients. In our study, D-dimer level was found to be high in 44 (53\%) patients. There were many studies showing that D-dimer was associated with proinflammatory cytokines in patients with poor clinical status or sepsis (18-22). That the alveolar haemostatic balance suppresses prothrombic activity in inflammatory conditions is considered a reason for this situation. In our study, a statistically significant relationship between D-dimer, CRP and ferritin is the one that supports the studies mentioned (23).

Viral pathogenicity is a well-known risk factor in chronic cardiovascular disease as a general consequence of the imbalance between an increased metabolic demand due to infection and decreased heart reserve. In the COVID-19 study of Han and his colleagues, CK-MB was found to be high in $3.6 \%$ of the patients, troponin was found to be high in $10.6 \%$ of the patients, and attention was drawn to the association of high cardiac enzymes with mortality. In this study, CK-MB was seen to be high in $2.4 \%$ patients and troponin I was seen to be high in $14.46 \%$ patients. Our cardiac enzyme levels were comparable with the values of patients with stable COVID-19 pneumonia observed by Han and his colleagues; however, in their study, cardiac levels of deceased and followed-up patients in intensive care units were higher $(24,25)$.

\section{Study limitations}

The number of the cases is rapidly increasing, but as we were seeking PCR test positivity and studying it only in the patients with COVID-19 pneumonia, this study was carried out in 83 patients. Some associations might not have achieved the substantial level due to low number of patients and single-tertiary centre nature of the research. However, we didn't want to waste time since we were in pandemic conditions. Since the number of the cases is increasingly rising, we will potentially follow up 4 or 5 times of these numbers in the coming weeks. Nonetheless, this study is valuable for our country on behalf of having early findings and raising awareness in future cases.

\section{Conclusion}

As a conclusion, we wanted to highlight the increasing parameters in COVID-19 rather than laboratory findings. We demonstrated that D-dimer, ferritin and CRP values were particularly high and we found a positive correlation between these parameters. We think that these parameters were closely associated with the patient's clinic, that they needed to be followed during hospitalization and that they could be valuable in the phase of evaluation of response to the treatment. Comorbidities were extremely important in terms of risk in such viral infections. Therefore, we investigated the comorbidity rate and prevalence frequency and in our study we noticed that comorbidities vary with the age.

\section{References}

1. COVID, C., Global Cases by Johns Hopkins CSSE. Gisanddata. maps. arcgis. com. Johns Hopkins University (JHU).

2. Organization WH. Clinical management of severe acute respiratory infection when novel coronavirus (2019-nCoV) infection is suspected: interim guidance, 28 January 2020. 2020, World Health Organization.

3. Bernheim A, Mei X, Huang M, Yang Y, Fayad ZA, Zhang N, Diao K, Lin B, Zhu X, Li K, Li S, Shan H, Jacobi A, Chung M. Chest CT findings in coronavirus disease-19 (COVID-19): relationship to duration of infection. Radiology 2020: p. 200463.

4. Guan WJ, Liang WH, Zhao Y, Liang HR, Chen ZS, Li YM, Liu XQ et al. Comorbidity and its impact on 1590 patients with Covid-19 in China: A Nationwide Analysis. Eur Resp J 2020.

5. Yang J, Zheng Y, Gou X, Pu K, Chen Z, Guo Q, Ji R, Wang H, Wang Y, Zhou Y. Prevalence of comorbidities in the novel Wuhan coronavirus (COVID-19) infection: a systematic review and meta-analysis. Internat J Infect Dis 2020.

6. McIntosh K. Coronaviruses, including severe acute respiratory syndrome (SARS)-associated coronavirus. Mandell, Douglas, and Bennett's Principles and Practice of Infectious Diseases, 2005: p. 1990-1997.

7. Han R, Huang L, Jiang H, Dong J, Peng H, Zhang D. Early clinical and CT manifestations of coronavirus disease 2019 (COVID-19) pneumonia. Amer J Roentgenol 2020: 1-6.

8. Wang F, Nie J, Wang H, Zhao Q, Xiong Y, Deng L, Song S, Ma Z, Mo P, Zhang Y. Characteristics of peripheral lymphocyte subset alteration in COVID-19 pneumonia. J Infect Dis 2020. 
9. Zhang G, Wang B, Zhu X, Wang Q, Qiu S. Analysis of clinical characteristics and laboratory findings of 95 cases of 2019 novel coronavirus pneumonia in Wuhan, China: a retrospective analysis. Respir Res 2020; 21 (1): $1-10$.

10. Qin C, Zhou L, Hu Z, Zhang S, Yang S, Tao Y, Xie C, Ma K, Shang K, Wang W, Tian DS. Dysregulation of immune response in patients with COVID-19 in Wuhan, China. China (February 17, 2020), 2020.

11. Liu Y, Yang Y, Zhang C, Huang F, Wang F, Yuan J, Wang Z, Li J, Li J, Feng C, Zhang $\mathbf{Z}$ et al. Clinical and biochemical indexes from 2019-nCoV infected patients linked to viral loads and lung injury. Science China Life Sci 2020; 63 (3): 364-374.

12. Chen T, Wu D, Chen H, Yan W, Yang D, Chen G, Ma K, Xu D, Yu H, Wang $\mathbf{H}$ et al. Clinical characteristics of 113 deceased patients with coronavirus disease 2019: retrospective study. BMJ 2020: 368.

13. Hlavaty T, Krajcovicova A. Novel unorthodox strategies to reduce the case fatality rate of COVID-19 in high risk groups including patients using ace inhibitors. Bratisl Med J 2020; 121 (7): 462-465. DOI: 10.4149/ BLL_2020_74.

14. Almirall J, Bolíbar I, Toran P, Pera G, Boquet X, Balanzó X, Sauca G. Contribution of C-reactive protein to the diagnosis and assessment of severity of community-acquired pneumonia. Chest 2004; 125 (4): 1335-1342.

15. Singhal T. A review of coronavirus disease-2019 (COVID-19). Indian J Pediatr 2020: 1-6.

16. Adams PC, Barton JC. A diagnostic approach to hyperferritinemia with a non-elevated transferrin saturation. J Hepatol 2011; 55 (2): 453-458.

17. Zhang JJ. Dong X, Cao YY, Yuan YD, Yang YB, Yan YQ, Akdis CA, Gao YD. Clinical characteristics of 140 patients infected with SARSCoV-2 in Wuhan, China. Allergy, 2020.
18. Chalmers JD, Singanayagam A, Scally C, T Hill A. Admission Ddimer can identify low-risk patients with community-acquired pneumonia. Ann Emerg Med 2009; 53 (5): 633-638.

19. Zhang Q, Wang Y, Qi C, Shen L, Li J. Clinical trial analysis of 2019nCoV therapy registered in China. J Med Virol 2020.

20. Långström S, Långström S et al. Enhanced thrombin generation and depressed anticoagulant function in children with pneumonia. Acta Paediatr 2012; 101 (9): 919-923.

21. Pettilä V, Hynninen M, Takkunen O, Kuusela P, Valtonen M. Predictive value of procalcitonin and interleukin 6 in critically ill patients with suspected sepsis. Intens Care Med 2002; 28 (9): 1220-1225.

22. Shorr AF, Thomas SJ, Alkins SA, Fitzpatrick TM, Ling GS. Ddimer correlates with proinflammatory cytokine levels and outcomes in critically ill patients. Chest 2002; 121 (4): 1262-1268.

23. Gunther A, Mosavi P, Heinemann S, Ruppert C, Muth H, Markart P, Grimminger F, Walmrath D. Alveolar fibrin formation caused by enhanced procoagulant and depressed fibrinolytic capacities in severe pneumonia: comparison with the acute respiratory distress syndrome. Amer J Respir Crit Care Med 2000; 161 (2): 454-462.

24. Madjid M, Casscells SW. Of birds and men: cardiologists' role in influenza pandemics. Lancet 2004; 364 (9442): 1309.

25. Han H, Xie L, Liu R, Yang J, Liu F, Wu K, Chen L, Hou W, Feng Y, Zhu C. Analysis of heart injury laboratory parameters in 273 COVID-19 patients in one hospital in Wuhan, China. J Med Virol 2020.

Received April 27, 2020. Accepted May 12, 2020. 